\title{
Ionic liquids as green reaction media for synthesis of poly(aryl ether ketone)s
}

\author{
WANG Jing \& LIU ZhengPing* \\ Institute of Polymer Chemistry and Physics of College of Chemistry, BNU Key Laboratory of Environmentally Friendly and Functional Polymer \\ Materials, Beijing Key Laboratory of Energy Conversion and Storage Materials, Beijing Normal University, Beijing 100875, China
}

Received September 26, 2012; accepted October 25, 2012; published online March 8, 2013

\begin{abstract}
Poly(aryl ether ketone)s (PAEKs) were successfully synthesized via nucleophilic aromatic substitution $\left(\mathrm{S}_{\mathrm{N}} \mathrm{AR}\right)$ mechanism, using ionic liquids as green reaction media. The influence of various reaction parameters including monomer concentration, dehydration time, polymerization temperature and duration, IL's cations and anions nature, upon PAEKs molecular weight was investigated. In addition, the peculiarities of hydrogen-bonding ability of ILs were investigated. The interaction of 2,2-bis(4-hydroxyphenyl) propane (bisphenol A) with ILs has a strong influence on PAEKs synthesis. Various moderate molecular weight PAEKs have been obtained in high yields with molecular weights ranging from 10000 to $18000 \mathrm{~g} \mathrm{~mol}^{-1}$.
\end{abstract}

high performance polymers, ionic liquids, poly(aryl ether ketone)s, polycondensation

Citation: Wang J, Liu Z P. Ionic liquids as green reaction media for synthesis of poly(aryl ether ketone)s. Chin Sci Bull, 2013, 58: 1262-1266, doi: $10.1007 / \mathrm{s} 11434-013-5741-2$

Poly (aryl ether ketone)s (PAEKs) belong to a category of materials known as special engineering thermoplastics, which exhibit many outstanding characteristics including excellent mechanical, thermooxidative and chemical resistance properties [1-3]. These polymers are expected to find use in engineering applications and membrane technology. One of the most recently developed of these materials is poly (ether ether ketone) (PEEK). Owing to the semicrystalline structure, high melting point and poor solubility in classical organic solvents, the application of this high performance polymer has been limited. It is well known that the incorporation of aliphatic chain into the polymer backbone is a tool to improve polymer solubility. Therefore, attempts have been made to develop new varieties of this material such as bisphenol A type PAEKs to improve the processing characteristics [4,5]. Generally, PAEKs were synthesized by the reaction of bisphenoxides with bis (aryl halides) via nucleophilic aromatic substitution $\left(S_{N} A R\right)$ mechanism [6]. The choices of solvents are usually $N, N$ -

*Corresponding author (email: lzp@bnu.edu.cn) dimethylacetamide and $N$-methyl-2-pyrolidone, which are volatile, flammable, toxic and harmful. Thus, removing organic solvents in polymer synthesis is a very important topic in the drive towards environmentally friendly technologies.

Recently, ionic liquids (ILs) attract more attention due to their low volatility, chemical stability, high thermal stability and ionic conductivity, etc [7-9]. Thus, ILs have become an alternative replacement for volatile organic compounds. In the last decades, high performance polymers such as polyimides and poly [naphthoylene bis-(benzimidazole)]s with high molecular weight were obtained in ILs as reaction medium [10]. A series of polyamides are generated in ILs coupling with microwave heating [11]. Moreover, aliphatic polyesters were successfully synthesized in sulfonic acid group-containing ILs [12]. Recently, our group developed a novel strategy to prepare high molecular weight polysulfone in imidazolium-based ionic liquids [13]. These forementioned studies demonstrate that the use of ILs has reactive effects on polymerization and make it possible to introduce ILs into polymer synthesis as green reaction media. However, 
the syntheses of high performance polymers especially PAEKs are still difficult. This is the first report of PAEKs synthesis in ionic liquids.

Herein, we present the development of new synthetic method for high performance PAEKs by using ILs as reaction media. Optimization of reaction conditions including the monomer concentration, dehydration time, polymerization temperature and duration was investigated. The interaction of ILs with bisphenol A was also studied. We intend to find an efficient way to gain high molecular weight of PAEKs. The structure of resulting polymers was confirmed by Elemental Analysis, FTIR and ${ }^{1} \mathrm{H}$ NMR spectroscopies.

\section{Experimental}

\subsection{Materials and methods}

$\mathrm{N}$-methylimidazole was distilled under reduced pressure. All alkyl halides (aladdin, 99\%), 1-butylimidazole (Aldrich, 98\%), 4,4'-difluorobenzophenone (DFB) and 2,2-bis(4-hydroxyphenyl) propane (bisphenol A) (aladdin, 98\%) were purified by recrystallizing from hot toluene. Ionic liquids and potassium carbonate were dried under vacuum before usage to eliminate the trace amount of water. Other solvents were utilized as received. ${ }^{1} \mathrm{H}$ NMR spectra were recorded on a Bruker Advance DRX-500 NMR spectrometer in DMSO- $d_{6}$ solutions. The molecular weight analysis was performed using a Polymer Laboratories gel permeation chromatograph (PL-GPC50) equipped with UV detector. The columns used are PL gel mixed-B by using chloroform

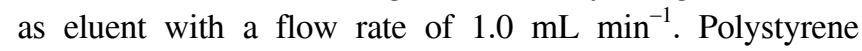
standards were used to calibrate the system.

\subsection{Preparation of ionic liquids}

All of the imidazolium based-ionic liquids used in this work were synthesized according to known procedures $[14,15]$. The structures of the ionic liquids were confirmed by ${ }^{1} \mathrm{H}$ NMR, FTIR and Elemental Analysis.

\subsection{Synthesis of PAEK in ionic liquid}

For a typical preparation of PAEK in ionic liquid, PAEK was synthesized within a $100 \mathrm{~mL}$ three-necked round flask equipped with a Dean-Stark trap, reflux-condenser, mechanical stirrer and nitrogen inlet. The flask was charged with 4,4'-difluorobenzophenone (0.646 g, $2.8 \mathrm{mmol})$ and bisphenol A $(0.639 \mathrm{~g}, 2.8 \mathrm{mmol})$ in $1.25 \mathrm{~g}$ of IL. The mixture was stirred vigorously with a constant purge of nitrogen and heated. After the homogeneous solution was heated up to $140^{\circ} \mathrm{C}$, anhydrous potassium carbonate $(0.46 \mathrm{~g}, 3.2 \mathrm{mmol})$ was added followed by $3 \mathrm{~mL}$ of toluene. The reaction mixture was refluxed under a Dean-Stark system with toluene at $150^{\circ} \mathrm{C}$ for $0.5 \mathrm{~h}$ until the accumulation of water was no longer evident in the Dean-Stark trap. Then toluene was removed by nitrogen atmosphere. The reaction mixture acquired a white and turbid suspension at the initial stage of the reaction due to the formation of the phenoxide. The reaction mixture was gradually heated to $180^{\circ} \mathrm{C}$ for $1.5 \mathrm{~h}$, and polymer was precipitated with the increase of viscosity of the polycondensation system. Then the reaction system was cooled down to room temperature. The product was obtained by simple filtration to separate the PAEKs and ILs. The resulting polymer was washed with methanol and hot water several times in order to remove inorganic salts and ILs, and then dried in vacuum at $60^{\circ} \mathrm{C}$ for $8-12 \mathrm{~h}$. IR ( $\mathrm{KBr}$, $\mathrm{cm}^{-1}$ ): 3200-3000 (Ar), 2963 (- $\mathrm{CH}_{3}$ asym-), $2845\left(-\mathrm{CH}_{3}\right.$ sym-), 1591, 1497 (C=C), $1654(\mathrm{C}=\mathrm{O}), 1240(\mathrm{C}-\mathrm{O}-\mathrm{C})$, $1169\left(-\mathrm{C}\left(\mathrm{CH}_{3}\right)_{2}\right), 837(\mathrm{Ar}-\mathrm{H}) .{ }^{1} \mathrm{H}$ NMR (DMSO- $\left.d_{6}, \mathrm{ppm}\right)$ : $\delta=6.97-7.79(16 \mathrm{H}, \mathrm{Ar}-\mathrm{H}), 1.70\left(6 \mathrm{H}, \mathrm{C}\left(\mathrm{CH}_{3}\right)_{2}\right)$.

\section{Results and discussion}

As we know, the synthesis of PAEKs needs high reaction temperature $\left(160-200^{\circ} \mathrm{C}\right)$ and polar solvents such as DMAc, NMP and DMSO [16]. Need for usage of high boiling solvents makes it a highly energy reaction. The unique feature of our approach is the synthesis of PAEKs in ILs as reaction media (Figure 1).

In this work, PAEKs were synthesized by the reaction of 4,4'-difluorobenzophenone (DFB) with bisphenol A via $S_{N} A R$ mechanism in the presence of anhydrous potassium carbonate, using ILs as reaction media. 1,3-dialkylimidazolium-based ILs, which have been the focus of polymer synthesis as environmentally benign solvents [17-19], were employed for synthesis of PAEKs. Toluene and anhydrous potassium carbonate were used as azeotroping solvent and

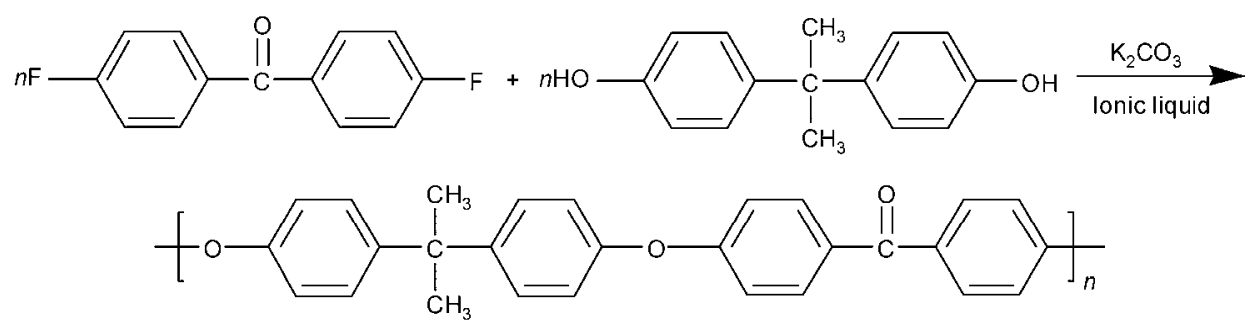

Figure 1 Synthesis of poly (aryl ether ketone)s in ionic liquids. 
salt forming agent respectively.

\subsection{Optimization of polycondensation conditions}

As we know, monomer concentration plays an important role in polycondensation and high concentration is usually preferred. The influence of monomer concentration on properties of PAEKs was first examined by using i-pmim $\mathrm{PF}_{6}$ as a model medium (Figure 2). The molecular weights of PAEKs gradually increased with increasing monomer concentration. The concentration dependence showed a maximum when the monomer concentration was $50 \%$ and high molecular weight PAEK $\left(M_{\mathrm{n}}=16900 \mathrm{~g} \mathrm{~mol}^{-1}\right)$ was synthesized. When the monomer concentration was higher than $50 \%$, the viscosity of reaction medium was very high leading to decreasing of the molecular weight of PAEKs.

Since the existence of water may induce the hydrolysis of bisphenol A potassium salt disturbing the stoichiometry of monomers, removal of water generated during phenoxide formation is an important influencing factor. Hence, sufficient dehydration time $(2.5-8.5 \mathrm{~h})$ is usually required to remove the generated water completely. The influence of dehydration time on the molecular weight of PEAKs was studied (Table 1, runs 1-4). With $0.5 \mathrm{~h}$ of dehydration time, $M_{\mathrm{n}}$ of PAEKs was up to $16900 \mathrm{~g} \mathrm{~mol}^{-1}$. The molecular weights of PAEKs were not improved by extending dehydration time. The dehydration property of the reaction process was monitored by visual inspection. A large amount of water was collected in Dean-Stark trap after $0.5 \mathrm{~h}$ of dehydration. Until $2.5 \mathrm{~h}$, the accumulation of water was no longer evident. Thus phenoxide forming reaction was assumed to be complete after dehydration for $0.5 \mathrm{~h}$, resulting in the highest molecular weight of PAEKs (Table 1, run 1). Then, experiments were carried out by optimization temperature. As the reaction temperature increased, molecular weights of PAEKs gradually increased. However, in the case of the reaction temperature at $190-200^{\circ} \mathrm{C}$ (Table 1 , runs 6 and 7),

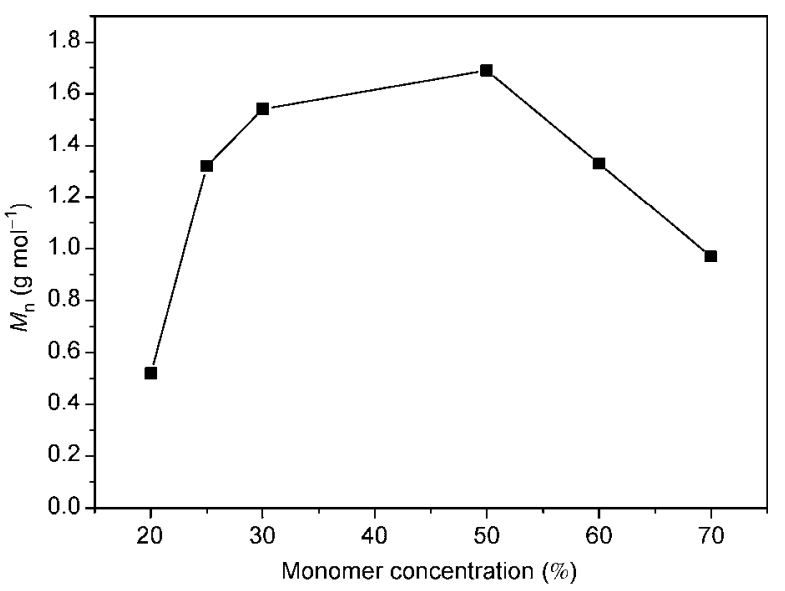

Figure 2 Influence of initial monomer concentration on molecular weight of PAEKs in i-pmim $\mathrm{PF}_{6}$ at $180^{\circ} \mathrm{C}$ for $1.5 \mathrm{~h}$.
Table 1 Effect of dehydration time, temperature and duration of polymerization on the synthesis of PAEKs ${ }^{\text {a) }}$

\begin{tabular}{ccccccc}
\hline Run & $\begin{array}{c}\text { Dehydration } \\
\text { time }(\mathrm{h})\end{array}$ & $\begin{array}{c}\text { Temp. } \\
\left({ }^{\circ} \mathrm{C}\right)^{\mathrm{b})}\end{array}$ & $\begin{array}{c}\text { Time } \\
(\mathrm{h})^{\mathrm{b})}\end{array}$ & $M_{\mathrm{n}}{ }^{\mathrm{c})}$ & PDI $^{\mathrm{c})}$ & $\begin{array}{c}\text { Yield } \\
(\%)\end{array}$ \\
\hline 1 & 0.5 & 180 & 1.5 & 16900 & 2.09 & $>99$ \\
2 & 1.5 & 180 & 1.5 & 17000 & 2.70 & $>99$ \\
3 & 2.5 & 180 & 1.5 & 18100 & 2.26 & $>99$ \\
4 & 3.5 & 180 & 1.5 & 18000 & 2.17 & $>99$ \\
5 & 1.5 & 170 & 1.5 & 7900 & 2.08 & 93.5 \\
6 & 1.5 & 190 & 1.5 & 15200 & 2.13 & 98.8 \\
7 & 1.5 & 200 & 1.5 & 12300 & 2.30 & 96.4 \\
8 & 1.5 & 180 & 0.5 & 6700 & 2.00 & 92.2 \\
9 & 1.5 & 180 & 2.5 & 16500 & 2.23 & $>99$ \\
10 & 1.5 & 180 & 3.5 & 15700 & 2.31 & $>99$ \\
\hline
\end{tabular}

a) General polymerization conditions: equimolar of bisphenol $\mathrm{A}$ and DFB, a little excess of $\mathrm{K}_{2} \mathrm{CO}_{3}, 50 \mathrm{wt} \%$ monomer concentration, dehydrate at $150^{\circ} \mathrm{C}$. Polymers were washed by hot water without further purification. b) Temperature and duration of polymerization. c) Number-average molecular weight $\left(M_{\mathrm{n}}\right)$ and polydispersity index (PDI) were measured by GPC calibrated with polystyrene standards.

molecular weight of PAEKs significantly decreased and the color of polymers became dark. This was probably caused by decomposition of PAEKs and ILs at high salt concentration or side effects such as cyclization at elevated temperatures. Therefore, we monitored the polymerization at $180^{\circ} \mathrm{C}$ with different reaction time. After only $0.5 \mathrm{~h}$ reaction, PAEK of $M_{\mathrm{n}}=6700 \mathrm{~g} \mathrm{~mol}^{-1}$ was obtained. After $1.5 \mathrm{~h}$, the molecular weight almost doubled. As the reaction reached equilibrium, the viscosity of reaction medium was very high hindering the movement of active functional group of oligomers, and the content of inorganic products increased, the molecular weight reached a plateau level after 2.5 and $3.5 \mathrm{~h}$. It is noteworthy that the resulting polymers are precipitated from solution at initial stage of the polycondensation. So the molecular weight of PAEKs was no longer increased with increasing polycondensation time. The following reaction parameters providing the polymer with highest molecular weight were seemed to be optimal: $50 \mathrm{wt} \%$ monomer concentration, dehydrate at $150^{\circ} \mathrm{C}$ for $0.5 \mathrm{~h}$, and then polymerize at $180^{\circ} \mathrm{C}$ for further $1.5 \mathrm{~h}$.

\subsection{IL's cations and anions nature}

The influence of ILs structure on the synthesis of PAEKs was investigated under the optimal reaction conditions. It can be observed that the best result was obtained in ILs with iso-propyl or iso-butyl alkyl chain due to their steric hindrance (Table 2, runs 2 and 6). With the increase of aryl substitution length, the molecular weights of resulting polymers were decreased. This may be explained by the decrease of polarity and poor solubility of ILs with longer alkyl chain.

As far as anions were concerned, the best results were 
Table 2 Effect of ILs nature on synthesis of PAEKs

\begin{tabular}{|c|c|c|c|c|c|c|}
\hline \multirow{2}{*}{ Run } & \multicolumn{3}{|c|}{ ILs } & \multirow{2}{*}{$M_{\mathrm{n}}$} & \multirow{2}{*}{ PDI } & \multirow{2}{*}{$\begin{array}{l}\text { Yield } \\
(\%)\end{array}$} \\
\hline & $\mathrm{R}_{1}$ & $\mathrm{R}_{2}$ & $\mathrm{Y}^{-}$ & & & \\
\hline 1 & $\mathrm{CH}_{3}$ & $\mathrm{i}-\mathrm{C}_{3} \mathrm{H}_{7}$ & $\mathrm{Br}$ & 7800 & 2.22 & 91.1 \\
\hline 2 & $\mathrm{CH}_{3}$ & $\mathrm{i}-\mathrm{C}_{3} \mathrm{H}_{7}$ & $\mathrm{PF}_{6}$ & 16900 & 2.09 & $>99$ \\
\hline 3 & $\mathrm{CH}_{3}$ & i- $\mathrm{C}_{3} \mathrm{H}_{7}$ & $\mathrm{BF}_{4}$ & 8600 & 1.91 & 89.7 \\
\hline 4 & $\mathrm{CH}_{3}$ & i- $\mathrm{C}_{3} \mathrm{H}_{7}$ & $\mathrm{Tf}_{2} \mathrm{~N}$ & 12900 & 1.78 & 93.5 \\
\hline 5 & $\mathrm{CH}_{3}$ & $\mathrm{C}_{4} \mathrm{H}_{9}$ & $\mathrm{PF}_{6}$ & 13600 & 1.73 & 95.6 \\
\hline 6 & $\mathrm{CH}_{3}$ & $\mathrm{i}-\mathrm{C}_{4} \mathrm{H}_{9}$ & $\mathrm{PF}_{6}$ & 17700 & 2.00 & 91.6 \\
\hline 7 & $\mathrm{C}_{4} \mathrm{H}_{9}$ & $\mathrm{C}_{4} \mathrm{H}_{9}$ & $\mathrm{PF}_{6}$ & 10700 & 1.77 & 76.3 \\
\hline 8 & $\mathrm{CH}_{3}$ & $\mathrm{C}_{6} \mathrm{H}_{13}$ & $\mathrm{PF}_{6}$ & 11200 & 2.00 & 97.3 \\
\hline 9 & $\mathrm{CH}_{3}$ & $\mathrm{C}_{8} \mathrm{H}_{17}$ & $\mathrm{PF}_{6}$ & 9600 & 1.98 & 98.2 \\
\hline
\end{tabular}

achieved in ILs with hexafluorophosphate counterion (Table 2 , runs $1-4$ ). It has been reported that $\mathrm{C}-2$ proton activity of imidazole, which can react with $\mathrm{KOH}$ or phenol, has strong influence on polymer synthesis [20,21]. Therefore, we examined the ${ }^{1} \mathrm{H}$ chemical shifts of bisphenol $\mathrm{A}$ in a series of ILs with different anions (Figure 3). ${ }^{1} \mathrm{H}$ NMR was performed in nonpolar and aprotic solvent of DMSO- $d_{6}$. It was seen that the chemical shifts of protons in benzene ring and methyl slightly changed, while the chemical shifts of C-2 proton increased with increasing anion basicity and hydrogen bonding ability $\left(\mathrm{PF}^{-}<\mathrm{Tf}_{2} \mathrm{~N}<\mathrm{BF}_{4}^{-}<\mathrm{Br}^{-}\right)$[22]. In addition, we found that no hydroxyl protons appeared in hydrophilic ILs such as i-pmim $\mathrm{BF}_{4}$ and i-pmim $\mathrm{Br}$. So we further examined the peak shifts of $\mathrm{C}-2$ proton in the mixture of different amount of bisphenol $\mathrm{A}$ and ILs (i-pmim $\mathrm{Br}$ and i-pmim $\mathrm{PF}_{6}$ ). As Figure 4 illustrated, when i-pmim $\mathrm{Br}$ was used, even with a small amount of bisphenol A, C2-position of imidazolium moiety significantly shifted to downfield, indicating strong interaction from electron-rich bisphenol A to electron-poor imidazolium cation. While the peak shifts ware quickly decreased with the increase of the amount of bisphenol A. On the contrary, in the mixture of bisphenol A

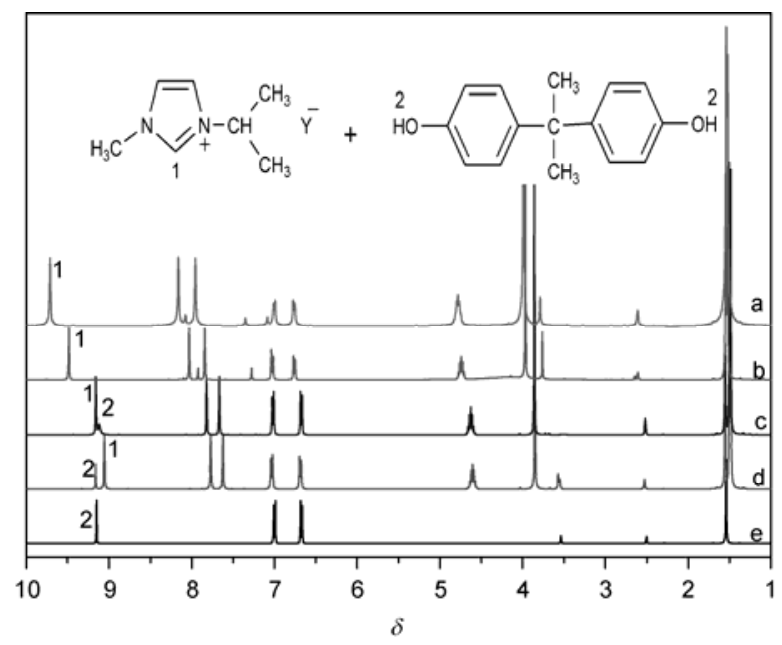

Figure $3{ }^{1} \mathrm{H}$ NMR spectra of bisphenol A in different solvents. a, i-pmim $\mathrm{Br} / \mathrm{DMSO}$; b, i-pmim $\mathrm{BF}_{4} / \mathrm{DMSO}$; c, i-pmim $\mathrm{Tf}_{2} \mathrm{~N} / \mathrm{DMSO}$; d, i-pmim $\mathrm{PF}_{6} / \mathrm{DMSO} ; \mathrm{e}, \mathrm{DMSO}$.

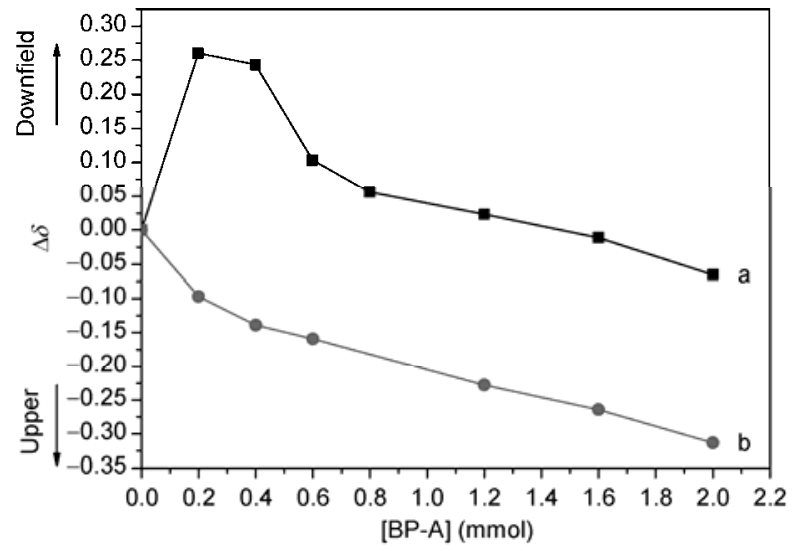

Figure 4 Values of peak shift of C2-position of imidazolium proton of i-pmim $\mathrm{Br}$ (a) and i-pmim $\mathrm{PF}_{6}$ (b) with varying concentration of phenol; ionic liquids $=0.25 \mathrm{~g}$, [bisphenol $\mathrm{A}]=0-2 \mathrm{mmol} \mathrm{L}^{-1}$.

and i-pmim $\mathrm{PF}_{6}$, hydroxyl proton and $\mathrm{C} 2$-position of imidazolium moiety slightly shifted to downfield and upper, respectively. The values of the peak shift were gradually increased with increasing amount of bisphenol A. We can conclude that the interaction of bisphenol A with ILs plays an important role in PAEKs synthesis. In hydrophilic ILs, the strong interaction of bisphenol A with imidazolium cation should reduce electron density of phenoxide. Thus, nucleophilic reactivity of bisphenol A decreased and steric hindrance of phenoxide increased, resulting in lower molecular weight PAEKs. In contrast with i-pmim $\mathrm{PF}_{6}$, the inter-action was too weak to inhibit the polymerization process, so high molecular weight PAEKs were prepared in ionic liquids with hexafluorophosphate counterion.

\subsection{Recovery and reuse of ionic liquids}

As an alternative to conventional organic solvents, recovery and reuse of ILs are absolutely important and necessary after polymerization. ILs in our study were separated with resulting polymers by soxhlet extraction. After that, the residual ILs in the filtrate were easily recovered by vacuum evaporation. The recycled i-pmim $\mathrm{PF}_{6}$ after one reaction cycle was analyzed by FTIR (Figure 5). It can be seen that there was no obvious change of the absorption bands of i-pmim $\mathrm{PF}_{6}$. Furthermore, the absorption peak at $838 \mathrm{~cm}^{-1}$ was appeared, which was assigned to the $\mathrm{P}-\mathrm{F}$ bond of $\mathrm{PF}_{6}^{-}$. The results showed that the ionic liquids underwent virtually no decomposition throughout the reaction. So the recycled ILs were used for a new polycondensation, and PAEK of slightly low molecular weight $\left(M_{\mathrm{n}}=13100 \mathrm{~g} \mathrm{~mol}^{-1}\right)$ was obtained. Therefore, the ILs recovered are able to be reused in new polymerization cycle.

\section{Conclusions}

In the present work, we describe a novel synthetic method 


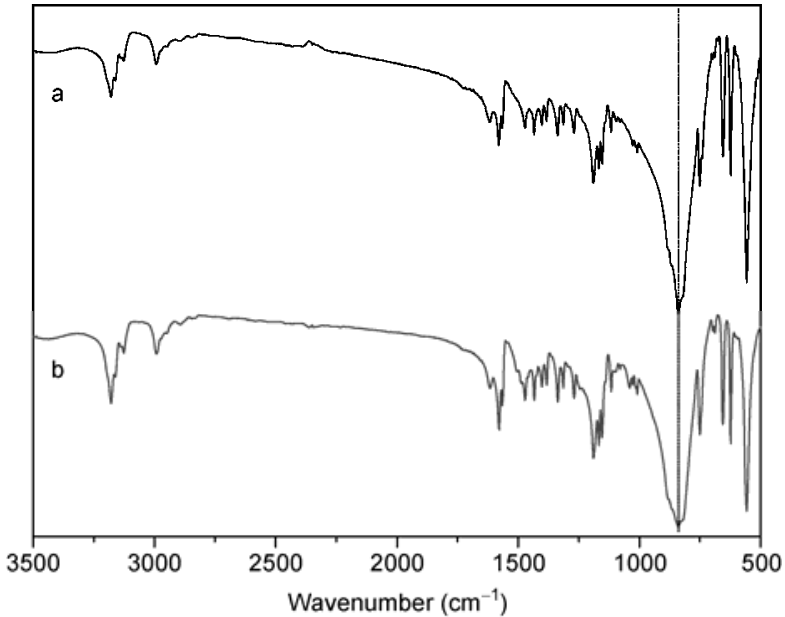

Figure 5 FTIR spectra of i-pmim $\mathrm{PF}_{6}$ as prepared (a), recycled (b).

for high performance PAEKs by using ionic liquids as reaction media. This is an outstanding application of ILs in polymer synthesis.

The study of optimization of polycondensation conditions has showed that PAEKs can be successfully synthesized in ionic liquids (50 wt\% monomer concentration, dehydrate at $150^{\circ} \mathrm{C}$ for $0.5 \mathrm{~h}$, polymerize at $180^{\circ} \mathrm{C}$ for further $1.5 \mathrm{~h})$. The number-average molecular weights of PAEKs are ranging from 10000 to $18000 \mathrm{~g} \mathrm{~mol}^{-1}$ with high yields. The influence of ILs nature upon polymer molecular weight has been studied as well. The molecular weights of PAEKs decreased with the increase of aryl substitution length. The interaction of bisphenol A with ILs strongly influences the polymerization process. $\mathrm{i}$-pmim $\mathrm{PF}_{6}$ was utilized as the best choice of solvents. The ionic liquids used in this work can be recycled and reused for the new polymerization cycle.

Ionic liquids have not only the alternative to organic solvents but also potential to increase chemical reactivity leading to more efficient processes. The syntheses of the most wide possible range of new materials in ionic liquids are in progress.

This work was supported by the National Natural Science Foundation of China (21274014), Beijing Municipal Commission of Education, the Fundamental Research Funds for the Central Universities and Measuring Fund of Large Apparatus of Beijing Normal University.

1 Chang M, Zhang X. Simulation of thermal characteristic parameters in the crystallization process of polyether-etherketone (PEEK). Chin Sci Bull, 1993, 38: 208

2 Perng L H, Tsai C J, Ling Y C. Mechanism and kinetic modelling of PEEK pyrolysis by TG/MS. Polymer, 1999, 40: 7321-7329
3 Roelofs K S, Hirth T, Schiestel T. Sulfonated poly(ether ether ketone)based silica nanocomposite membranes for direct ethanol fuel cells. $\mathrm{J}$ Membr Sci, 2010, 346: 215-226

4 Zhao Y, Yin J. Synthesis and properties of poly(ether ether ketone)block-sulfonated polybutadiene copolymers for PEM applications. Eur Polym J, 2010, 46: 592-601

5 Nakamura M, Ishida H. Synthesis and properties of new crosslinkable telechelics with benzoxazine moiety at the chain end. Polymer, 2009, 50: 2688-2695

6 Mani R S, Zimmerman B, Bhatnagar A, et al. Poly(aryl ether ketone) synthesis via competing SNAR and SRN1 reactions. 1. Polymers derived from 1,3-bis(p-chlorobenzoyl)benzene and 1,3-bis(p-fluorobenzoyl) benzene with hydroquinone and 4,4'-isopropylidenediphenol. Polymer, 1993, 34: 171-181

7 Fu H Y, Xing Z G, Cao X Y, et al. Pulse radiolysis studies of functionally substituted imidazolium-based ionic liquids. Chin Sci Bull, 2012, 57: 2752-2758

8 Yang W, He X J, Gao J Z, et al. Synthesis, characterization, and tunable wettability of poly(ionic liquid) brushes via nitroxide-mediated radical polymerization (NMP). Chin Sci Bull, 2010, 55: 3562-3568

9 Zhao T K, Liu L H, Li G M, et al. Preparation and electrochemical property of CMC/MWCNT composite using ionic liquid as solvent. Chin Sci Bull, 2012, 57: 1620-1625

10 Vygodskii Y S, Lozinskaya E I, Shaplov A S, et al. Implementation of ionic liquids as activating media for polycondensation processes. Polymer, 2004, 45: 5031-5045

11 Mallakpour S, Dinari M. A study of the ionic liquid mediated microwave heating for the synthesis of new thermally stable and optically active aromatic polyamides under green procedure. Macromol Res, 2010, 18: 129-136

12 Dukuzeyezu E M, Lefebvre H, Tessier M, et al. Synthesis of high molar mass poly(12-hydroxydodecanoic acid) in bronsted acid ionic liquids. Polymer, 2010, 51: 1218-1221

13 Wang J, Liu Z P. An efficient synthetic strategy for high performance polysulfone: Ionic liquid/zwitterion as reaction medium. Green Chem, 2012, 14: 3204-3210

14 Wilkes J S. A short history of ionic liquids-from molten salts to neoteric solvents. Green Chem, 2002, 4: 73-80

15 Ge M L, Xiong J M, Wang L S, et al. Theoretical prediction for the infinite dilution activity coefficients of organic compounds in ionic liquids. Chin Sci Bull, 2009, 54: 2225-2229

16 Devaux J, Delimoy D, Daoust D, et al. On the molecular weight determination of a poly(aryl-ether-ether-ketone) (PEEK). Polymer, 1985, 26: 1994-2000

17 Frank H, Ziener U, Landfester K. Formation of polyimide nanoparticles in heterophase with an ionic liquid as continuous phase. Macromolecules, 2009, 42: 7846-7853

18 Minami H, Tarutani Y, Yoshida K, et al. Preparation of nylon-6 particles in ionic liquids. Macromol Symp, 2010, 288: 49-54

19 Dali S, Lefebvre H, El Gharbi R, et al. Synthesis of poly(glycolic acid) in ionic liquids. J Polym Sci, Part A: Polym Chem, 2006, 44: 3025-3035

20 Singh N, Singh S K, Khanna R S, et al. Ionic liquid/potassium hydroxide catalyzed solvent-free, one-pot synthesis of diarylglycolic acids from aromatic aldehydes under microwave. Tetrahedron Lett, 2011, 52: 2419-2422

21 Ogoshi T, Onodera T, Yamagishi T, et al. Green polymerization of phenol in ionic liquids. Macromolecules, 2008, 41: 8533-8536

22 Lungwitz R, Friedrich M, Linertc W, et al. New aspects on the hydrogen bond donor (HBD) strength of 1-butyl-3-methylimidazolium room temperature ionic liquids. New J Chem, 2008, 32: 1493-1499

Open Access This article is distributed under the terms of the Creative Commons Attribution License which permits any use, distribution, and reproduction in any medium, provided the original author(s) and source are credited. 